\title{
Design and Fabrication of a Manually Operated Hydraulic Press
}

\author{
Fisayo Adesina1, Tiamiyu Ishola Mohammed ${ }^{2}$, Oluwole Timothy Ojo $^{3 *}$ \\ ${ }^{1}$ Department of Mechanical Engineering, Rufus Giwa Polytechnic, Owo, Nigeria \\ ${ }^{2}$ Department of Mechanical Engineering, The Federal University of Technology, Akure, Nigeria \\ ${ }^{3}$ Department of Industrial and Production Engineering, The Federal University of Technology, Akure, Nigeria \\ Email: *wolex025@gmail.com
}

How to cite this paper: Adesina, F., Mohammed, T.I. and Ojo, O.T. (2018) Design and Fabrication of a Manually Operated Hydraulic Press. Open Access Library Journal, 5: e4522.

https://doi.org/10.4236/oalib.1104522

Received: March 19, 2018

Accepted: April 23, 2018

Published: April 26, 2018

Copyright $\odot 2018$ by authors and Open Access Library Inc.

This work is licensed under the Creative Commons Attribution International License (CC BY 4.0).

http://creativecommons.org/licenses/by/4.0/ (c) (i) Open Access

\begin{abstract}
The paper presents the development of a manually operated hydraulic press which encompasses the design, fabrication and performance evaluation of the press. The components parts of the machine were designed using various design equations. The design results were used to select materials for various components. The detailed drawing of the developed machine was done using Pro E software. In fabricating the machine, mild steel was used as the locally sourced material. The use of mild steel is due to the fact that its strength, rigidity and machinability falls within the design specifications. Some components of the machine developed include; the frame, cylinder mounting table, press pin, working table/bed, hydraulic tank, and hand lever. Some of the bought out parts include: ram assembly, pressure hose, pressure indicator and hydraulic pump. In evaluating the performance of the machine developed, mild steel plate of length $220 \mathrm{~mm}$, breadth $70 \mathrm{~mm}$ and thickness $20 \mathrm{~mm}$ was put on the machine working table. This piece of material was bent after pressing the hand lever. The pressure at which bending took place was read to be 50 bar as indicated on the pressure gauge. The machine developed was also used to press a sleeve of internal diameter of $85 \mathrm{~mm}$ and external diameter of $89 \mathrm{~mm}$ into the cylinder of an engine block at a pressure of 15 bar. The cost of the machine as at the time of fabrication is $\mathrm{N} 398,440$.
\end{abstract}

\section{Subject Areas}

Mechanical Engineering

\section{Keywords}

Design, Fabrication, Performance Evaluation, Hydraulic Press 


\section{Introduction}

Presses are pressure exerting machine tools. They are used in industry for the cold working of metallic object into a variety of shapes through operations such as blanking, piercing, chawing, forming, bending and shearing. It represents an important part of manufacturing industry being used for cheap production of large quantities of components such as motor car bodies, electric motor parts and domestic electrical appliances parts. All presses consist of a machine frame supporting a bed, a ram, a source of power and a prime mechanism. Orthodox press may be hydraulic or pneumatic or may be mechanical crank presses. Hydraulic deals with the law governing the equilibrium and motion of fluid and their application to the solution of specific problems in various fields of engineering [1].

The hydraulic press is an invaluable equipment in the workshop and laboratories especially for press fitting operations and for the deformation of materials such as in metal forming processes and material testing for strength [2]. A hydraulic press is a device using a hydraulic cylinder to generate a compressive force. It uses the hydraulic equivalent of a mechanical lever, and was also known as a Bramah press after the inventor, Joseph Bramah of England [3]. He invented and was issued a patent on this press in 1795. As Bramah (who is also known for his development of the flush toilet) installed toilets, he studied the existing literature on the motion of fluids and put this knowledge into the development of the press [4]. Hydraulic presses are preferred when very large nominal force is required [5]. Presses can be classified into three major categories as: hydraulic presses which operate on the principles of hydrostatic pressure, mechanical presses which utilize kinematic linkage of elements to transmit power and screw presses which use power screws to transmit power [6].

The development of engineering over the years has been the study of finding ever more efficient and convenient means of pushing and pulling, rotating, thrusting and controlling load, ranging from a few kilograms to thousands of tons. Presses are widely used to achieve this [2].

Several researches have been carried out on the design and fabrication of presses. [2] designed, constructed and tested a 30-ton hydraulic press using locally sourced materials. The principal parameters of the design included the maximum load $(300 \mathrm{kN})$, the distance the load resistance has to move (piston stroke, $150 \mathrm{~mm}$ ), the system pressure, the cylinder area and the volume flow rate of the working fluid.

[7] researched on Structural Optimization of 5 Ton Hydraulic Press and Scrap Baling Press for Cost Reduction by Topology. Topology optimization was applied on various components of scrap baling press and 5 Ton hydraulic press using ANSYS WORKBENCH software. Suitable loads and constraints were applied on the initial design space of the components. An integrated approach was also developed to verify the structural performance by using ANSYS software. At the end, shape optimized design model was compared with the actual part that 
was being manufactured for the press. It was inferred that topology optimization results in a better and innovative product design. [8] designed and fabricated a Hydraulic Press for the Production of Kiln Shelves. The design and fabrication of the machine was done according to laid down engineering and industrial design procedures ethics and codes. [9] [10] worked on the Analysis and Structural Optimization of 5 Ton H-Frame Hydraulic Press. The report opined that using the optimum resources possible in designing the hydraulic presses frame can effect reduction in the cost of the hydraulic presses by optimizing the weight of material utilized for building the structure.

A critical look at mechanical workshops in Nigeria reveals that majority of press machines are imported into the country and this is done at high cost. Hence, it is expedient that more of such important machine be developed locally [2]. This work therefore presents the development of manually operated hydraulic press, which is of low cost, hydraulically operated and can compete favourably with imported press machines of the same designed capacity. The development of more of this machine will help to minimize high cost of purchasing and importation of this machine thereby strengthen our local manufacturing industries.

\section{Methodology}

In achieving the aim of this work, component parts of the machine were designed using various design equations. The design results were used to select materials for various components. The detailed drawing of the developed hydraulic press machine was done using Pro $\mathrm{E}$ software. In fabricating the machine, mild steel was used as the locally sourced material. The use of mild steel is due to the fact that its strength, rigidity and machinability falls within the design specifications. It is also available and cost effective.

\subsection{Design Analysis of Some Machine Components}

Some components parts of the machine developed include; the frame (stand, base support, column, top plate), cylinder mounting table, press pin, working table/bed, cylinder/ram assembly, hydraulic tank, hand lever, pressure hose, pressure indicator and hydraulic pump.

\subsubsection{Machine Frame}

A frame is a structure on which main units of a machine tool are assembled. For this work, the frame was designed to accommodate ram assembly, hydraulic pump, oil thank, and working table (bed). The design consideration is that of direct tension imposed on the pillars. Other frame members are subjected to simple bending stresses.

\subsubsection{Determination of Volume of Hydraulic Tank}

The volume of hydraulic tank was calculated from the Equation (1);

$$
V=L W H
$$


where $L$ is the length of the tank in metres, $W$ is the Width of the tank in metres, $H$ is the height of the tank in metres.

\subsubsection{Design for Bolts}

The diameter of bolt was determined from Equation (2) according to Khurmi and Gupta, 2005:

$$
P=\frac{\pi}{4}\left(d_{c}\right)^{2} \sigma_{t} n
$$

where: $P$ is the external load acting on the cover plate, $d_{c}$ is the core diameter of the bolt thread, $\sigma_{t}$ is the allowable tensile stress for bolt material, $n$ is the number of bolt

$$
\text { but } P=\frac{\pi}{4}(D)^{2} p
$$

where: $p$ is the maximum pressure, $D$ is the inside diameter of cylinder.

\subsubsection{Determination of Tensile Stress Due to Stretching of Bolt}

Initial tension in a bolt based on experiments may be found by the relationship in Equation (4) as given by Sumaila and Ibhadode, 2011.

$$
P_{i}=2840 d(N)
$$

where $P_{i}$ is the initial tension in a bolt $(N), d$ is the nominal bolt diameter

\subsubsection{Determination of Stress Area on the Bolt}

Stress area on the bolt was found using the relation in Equation (5) as given by Khurmi and Gupta, 2005:

$$
\text { Stress Area }=\frac{\pi}{4}\left(\frac{d_{p+d_{c}}}{2}\right)^{2}
$$

where $d_{p}$ is the pitch diameter, $d_{c}$ is the core or minor diameter.

\subsubsection{Determination of Weight of the Piston of the Hydraulic Press} The weight of piston was determined from Equation (6)

$$
\text { Density of metal }(\rho)=\frac{\text { Mass of metal }(m)}{\text { Volume of piston }(V)_{p}}
$$

But density of metal $\rho_{m}=7850 \mathrm{~kg} / \mathrm{m}^{3}$

$$
\text { Volume of piston }\left(V_{p}\right)=\pi r^{2} h
$$

Mass of Piston, $M_{p}=\rho_{m} V_{p}$

$$
\text { And Weight of Piston }\left(W_{p}\right)=m_{p} \text { g }
$$

\subsubsection{Determination of the Weight of Press Cylinder}

The weight of press cylinder was determined by applying Equation (9)

$$
\text { Weight of cylinder }\left(W_{c}\right)=\rho_{m} V_{c} \mathrm{~g}
$$

where $V_{c}$ is the volume of cylinder 


$$
V_{c}=\pi\left(r_{2}^{2}-r_{1}^{2}\right) h
$$

$h$ is the height of cylinder, $r_{1}$ is the internal radius, $r_{2}$ is the outer radius.

\subsubsection{Determination of Oil Flow Rate}

Oil flow rate of the pump was determined using Equation (11):

$$
Q=A V
$$

where $Q$ is the flow rate in $\mathrm{m}^{3} / \mathrm{s}, V$ is the velocity of flow in $\mathrm{m} / \mathrm{s}, A$ is the area of pipe in $\mathrm{m}^{2}$.

Equation (12) was used to determine the hydraulic power of the machine

$$
\text { Hydraulic Power } P_{h}=Q \rho g h
$$

where $Q$ is the flow rate in $\mathrm{m}^{3} / \mathrm{s}, \rho$ is the density of oil in $\mathrm{kg} / \mathrm{m}^{3}, g$ is the acceleration due to gravity in $\mathrm{m} / \mathrm{s}^{2}, h$ is the differential head in metres $(\mathrm{m})$.

Some of the design values obtained for hydraulic press machine are presented in Table 1.

The shear force and bending moment diagrams for a load of $300 \mathrm{kN}$ on the machine frame is presented in Figure 1.

\subsection{Detailed Drawings of the Machine}

The detailed Isometric view and Orthographic view of the machine are shown in Figure 2 respectively.

\subsection{Machine Fabrication Processes}

The various processes used in the fabrication of this hydraulic press machine include: Measurement, Marking out, Cutting, Drilling, Welding, Fastening, Grinding and Painting.

\section{Assembly and Welding of Machine Components}

In welding various components of this machine together, electric arc welding technique was used because of the ease of concentration of heat. Heat spread reduces buckling and warping. The heat concentration also increases the depth of penetration and speeds up the welding operation. The base which is made of U Channel mild steel was first set up. The base has a length of $840 \mathrm{~mm}$, breadth of $180 \mathrm{~mm}$ and thickness of $6 \mathrm{~mm}$. The column which is made of four pieces of vertical flat mild steel plate was welded to the base that has been set up. Each of the plate has length of $1650 \mathrm{~mm}$ (vertical height), breadth of $102 \mathrm{~mm}$ and thickness of $20 \mathrm{~mm}$. They were all welded to the base to form the column of the machine. Having done this, two pieces of flat mild steel plate (length of $840 \mathrm{~mm}$, breadth of $225 \mathrm{~mm}$ and thickness of $16 \mathrm{~mm}$ ) were welded to the top part of the frame. With all the major frame parts in firm position, the frame stand was welded to the base of the frame to provide for stability of the machine during operations.

Three holes of $50 \mathrm{~mm}$ in diameter was made on each of the column. This is to give room for adjustment of the bed (table). Also, a rectangular oil tank of (203.2 $\times 203.2 \times 209.5) \mathrm{mm}$ was fabricated and welded to the centre part of the column 
Table 1. Some designed values for the hydraulic press.

\begin{tabular}{ccc}
\hline S/N & Design Factor & Design Values \\
\hline $\mathbf{1}$ & Volume of Hydraulic tank & $0.00867 \mathrm{~m}^{3}$ \\
$\mathbf{2}$ & Core diameter, $d_{c}$ & $7 \mathrm{~mm}$ \\
$\mathbf{3}$ & External load acting on bolt and nut & $28.3 \mathrm{KN}$ \\
$\mathbf{4}$ & Initial tension in a bolt, $P_{i}$ & $14.5 \mathrm{~N}$ \\
$\mathbf{5}$ & Stress area & $7.28 \times 10^{-6} \mathrm{~m}^{2}$ \\
$\mathbf{6}$ & Weight of piston, $W_{p}$ & $42.4 \mathrm{~N}$ \\
$\mathbf{7}$ & Weight of Cylinder, $W_{c}$ & $150 \mathrm{~N}$ \\
$\mathbf{8}$ & Velocity of flow of fluid, $V_{f}$ & $4.22 \mathrm{~m} / \mathrm{s}$ \\
$\mathbf{9}$ & Oil flow rate, $Q$ & $0.00133 \mathrm{~m} / \mathrm{s}$ \\
$\mathbf{1 0}$ & Hydraulic Power, $P_{h}$ & $10.8 \mathrm{~W}$ \\
\hline
\end{tabular}

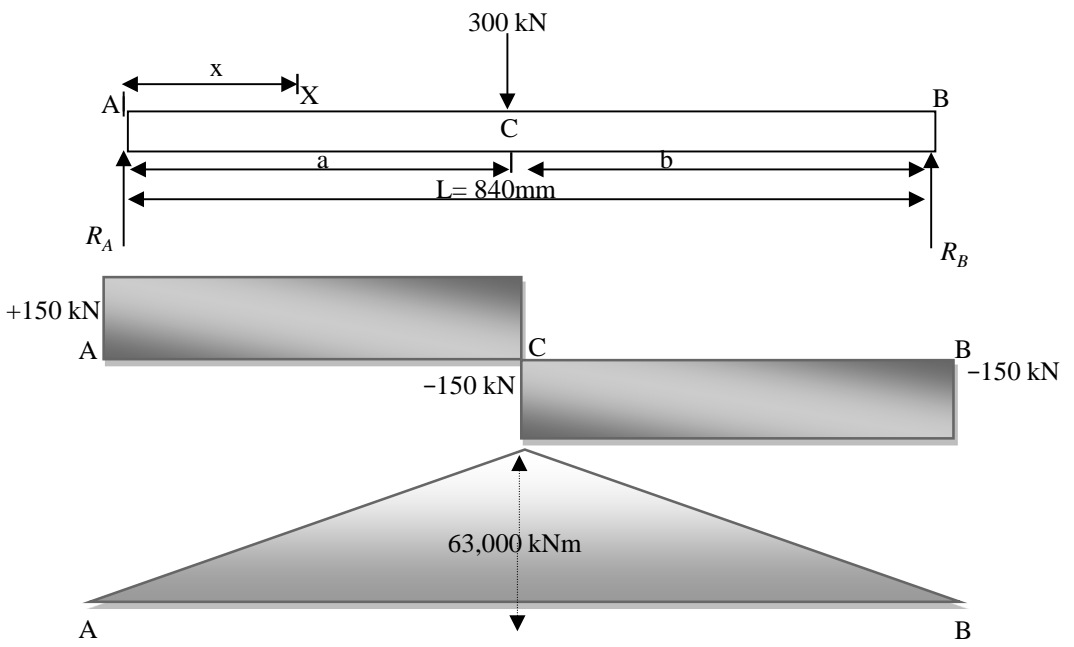

Figure 1. Shear force and bending moment diagrams for a simply supported beam with a point load of $300 \mathrm{kN}$.

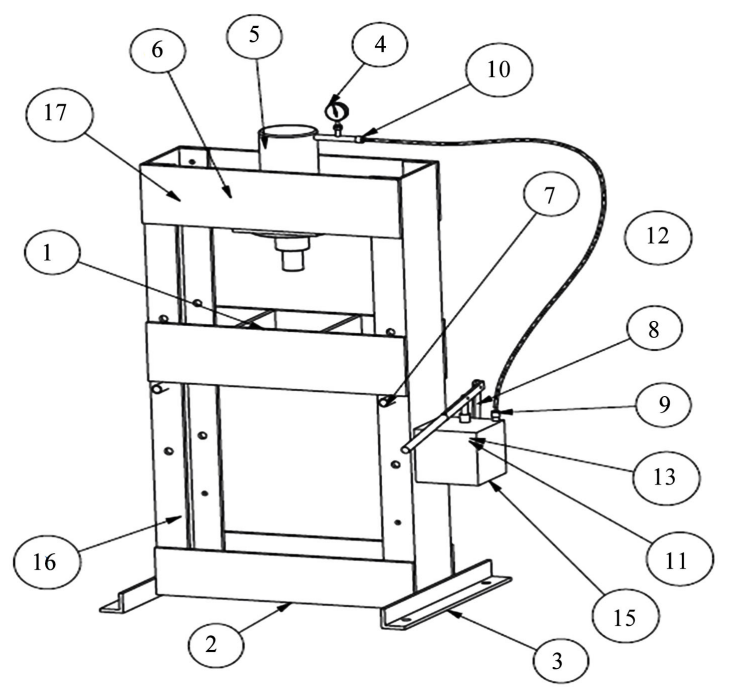

\begin{tabular}{|l|l|l|}
\hline S/N & PARTS & QTY \\
\hline 1 & BED & 1 \\
\hline 2 & BOTTOM_CROSS_MEMBER & 2 \\
\hline 3 & FLOOR_SUPPORT & 2 \\
\hline 4 & GAUGE & 1 \\
\hline 5 & HEAD_STOCK & 1 \\
\hline 6 & HEAD_SUPPORT & 1 \\
\hline 7 & HOOK & 2 \\
\hline 8 & LINK & 1 \\
\hline 9 & PRESSURE_CAP & 1 \\
\hline 10 & PRESSURE_PIPE_CAP2 & 1 \\
\hline 11 & PRESSURE_PISTON & 1 \\
\hline 12 & PRESURE_ROD & 1 \\
\hline 13 & PUMP_PISTON_SEAL & 3 \\
\hline 14 & RESERVOIR_SUPPORT & 1 \\
\hline 15 & RESEVIOUR & 1 \\
\hline 16 & SIDE_SUPPORT & 2 \\
\hline 17 & UPPER_CROSS_MEMBER & 2 \\
\hline
\end{tabular}

Figure 2. Isometric drawing of the machine and part list. 
of the machine frame. This tank serves as oil reservoir needed to pump the hydraulic pump. A hand operated lever which is made of mild steel rod of $610 \mathrm{~mm}$ length and $25 \mathrm{~mm}$ thickness was connected to oil tank with the aid of a pivot. SAERI2 Pressure hose was fitted to the hydraulic oil tank in order to convey hydraulic oil from the tank to a single acting hydraulic pump which is mounted on the top part of the frame. The hydraulic pump has a load capacity of 30 tons. All the machine parts were firmly secured to ensure rigidity and support. The finishing of the fabricated machine involves grinding the welded joints and painting with emulsion paint.

\section{Results and Discussion}

The developed manually operated hydraulic press was achieved by following the stated objectives of this work. The machine developed was made from locally sourced materials. Mild steel was used in fabricating majority of the components of the machine. One important feature of this press machine is interchangeability of mould and die without dismantling the ram assembly.

The machine developed is shown in Figure 3. Figure 4(a) Shows cylinder engine block before pressing sleeve into it while Figure 4(b) shows cylinder engine block after pressing of sleeve using the developed press machine. Bending of 20 $\mathrm{mm}$ Steel Plate is presented in Figure 5(a) while Figure 5(b) shows the demostration of plate folding. Figure 6(a) shows a Punch, Die and steel plate before bending while Figure 6 (b) show the folded plate.

Prior to machine performance evaluation, machine frame, structural members, weld, pump and cylinder mechanism were inspected in order to check for any fault or leakages of hydraulic oil. Tests were carried out on the multipurpose press machine by using it to press different metals (materials) at maximum pressure. The hydraulic press machine developed was used to perform various press works. The machine worked without any challenge as there was no distortion, deformation, no weld failure, no leakages and the operation of hydraulic pump, ram and pump mechanism was quite satisfactory under the varying loads.

In evaluating the performance of the machine developed, mild steel plate of length $220 \mathrm{~mm}$, breadth $70 \mathrm{~mm}$ and thickness $20 \mathrm{~mm}$ was put on the machine working table. This piece of material was bent after pressing the hand lever. The pressure at which bending took place was read to be 50 bar as indicated on the pressure gauge. Also, a $3 \mathrm{~mm}$ steel plate of $290 \mathrm{~mm} \times 225 \mathrm{~mm}$ was placed on the machine working table (bed) to be bent. It was noted that bending of this pate started at a pressure of 15 bar and maximum bending was taken to be 20 bar. The machine developed was also used to press a sleeve of internal diameter of 85 $\mathrm{mm}$ and external diameter of $89 \mathrm{~mm}$ into the cylinder of an engine block at a pressure of 15 bar. Other press operations which the machine could perform include but not limited to deep drawing, cup drawing, shallow drawing and stamping. 


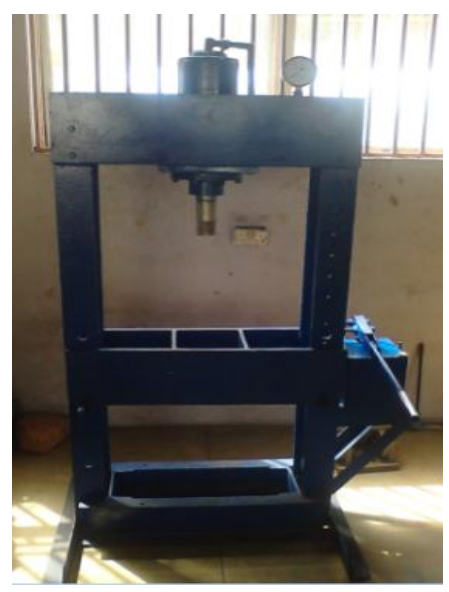

Figure 3. The fabricated hydraulic press machine.

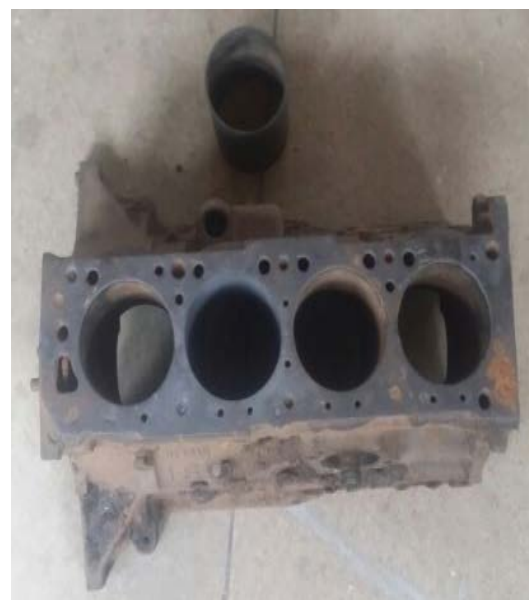

(a)

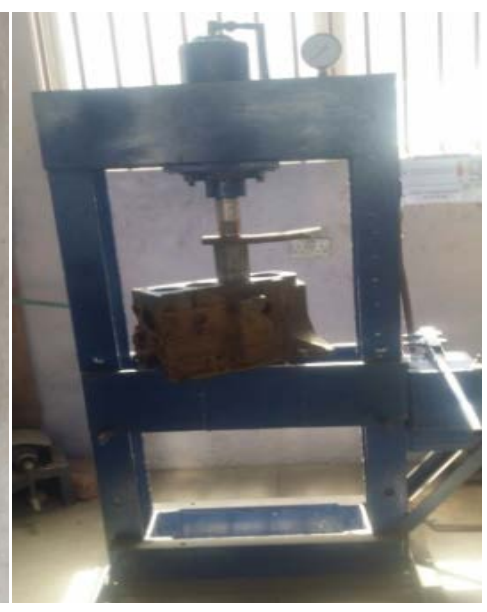

(b)

Figure 4. (a) Cylinder engine block before pressing sleeve; (b) Cylinder engine block after the pressing of sleeve.

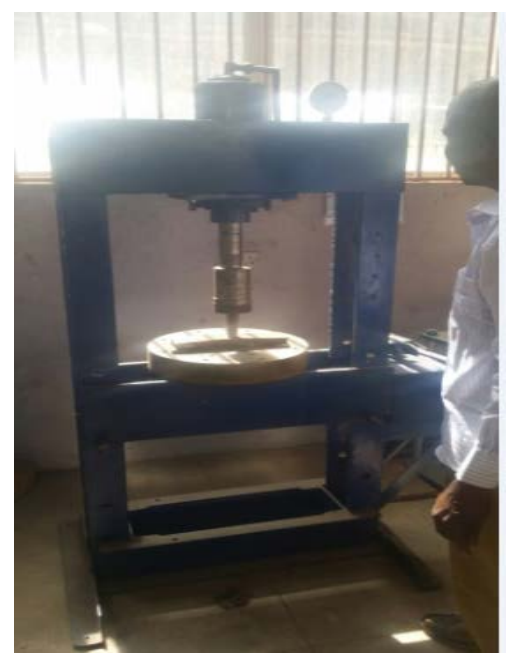

(a)

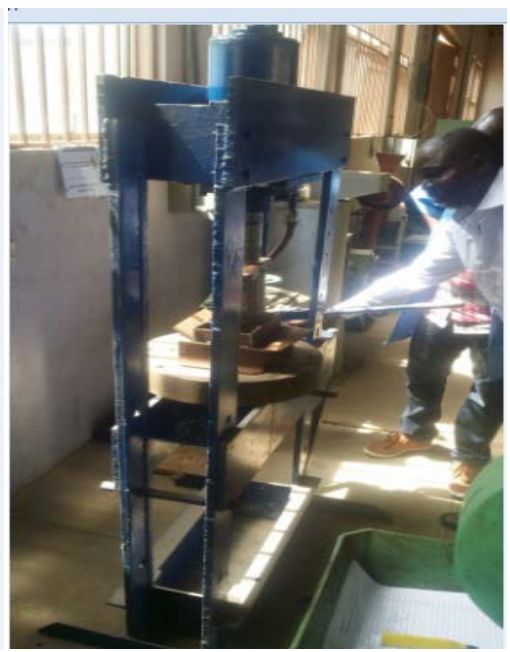

(b)

Figure 5. (a) Bending of $20 \mathrm{~mm}$ steel plate; (b) Plate folding. 


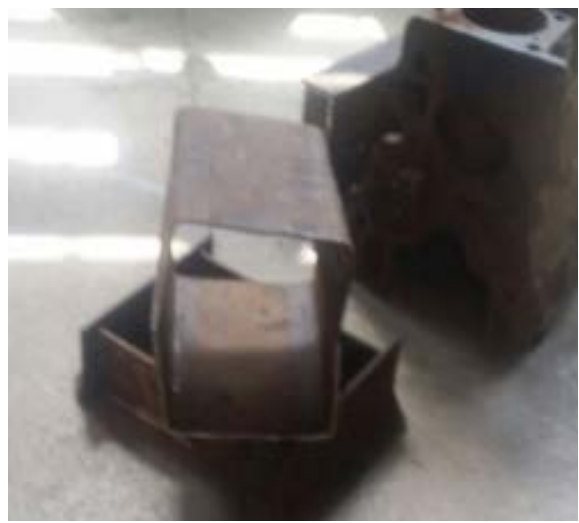

(a)

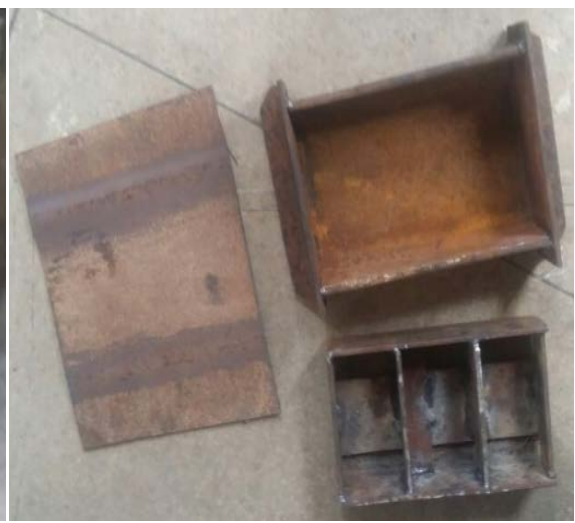

(b)

Figure 6. (a) Steel plate before bending, punch and die; (b) The folded plate.

\section{Conclusion}

A hydraulic press machine has been developed. The machine was fabricated using locally made materials. The machine is capable of performing various press works. Various machine parts such as pump, hand lever, ram assembly and pressure gauge worked effectively and efficiently. Some of press work operations performed on the machine include: bending, punching, drawing and stamping. The machine was also used to press sleeves of internal diameter of $85 \mathrm{~mm}$ and external diameter of $89 \mathrm{~mm}$ into the cylinder of an automobile engine block at a pressure of 15 bar. Performance evaluation of the machine shows that it can compete favourably with imported press machines of the same designed capacity. The cost of developing the machine locally as at the time of fabrication was $\mathrm{N} 398,440$ (\$2000) compared to the cost of purchasing the imported ones of same capacity which ranges from $\$ 5000$ to $\$ 15,000$ excluding cost of importation. The development of more of this important workshop machine is expected to boost our local manufacturing industries.

\section{Acknowledgements}

The Authors would like to acknowledge Bukola Adesina who contributed immensely to the success of this work.

We declare that no funding was received from any source as financial support for this research.

\section{References}

[1] Jain, R.K. (2012) Production Technology. 17th Edition, Khanna Publishers, New Delhi, 806-824.

[2] Sumaila, M. and Ibhadode, A.O.A. (2011) Design and Manufacture of a 30-Ton Hydraulic Press. Assumption University Journal of Technology, 14, 196-200.

[3] Parker, D.T. (2013) Building Victory: Aircraft Manufacturing in the Los Angeles Area in World War II. Cypress, Canada, 20-87.

[4] Carlisle, R. (2004) Scientific American Inventions and Discoveries. John Wiley \& Sons, Inc., New Jersey, 266. 
[5] Lange, K. (1975) Handbook of Metal Forming. McGraw-Hill, New York.

[6] Sharma, P.C. (2005) A Textbook of Production Engineering, 10th Edition, S. Chard and Company Ltd, New Delhi, 69-146.

[7] Muni, P. and Amarnath V. (2011) Structural Optimization of 5 Ton Hydraulic Press and Scrap Baling Press for Cost Reduction by Topology. International Journal of Modeling and Optimization, 3, 185-190.

[8] Ayodele, O.D., Ahuwan, A. M., Sullayman, U.A.A. and Yawas, D.S. (2005) Design and Fabrication of a Hydraulic Press for the Production of Kiln Shelves. Journal of Chemical, Mechanical and Engineering Practice, 3, 26-36.

[9] Santoshkumar, S.M., Yogita N.P. and Mattikalli, A.C. (2014) Analysis and Structural Optimization of 5 Ton H-Frame Hydraulic Press. International Journal of Innovative Science, Engineering and Technology, 5, 356-360.

[10] Sharma, P.C. (2005) A Textbook of Production Engineering. 10th Edition, S. Chard and Company Ltd, New Delhi, 69-146. 